\title{
1 Metabolite damage and repair in metabolic engineering design
}

2

3 Jiayi Sun ${ }^{a}$, James G. Jeffryes ${ }^{b}$, Christopher S. Henry ${ }^{b, c}$, Steven D. Bruner ${ }^{d}$, Andrew D. Hanson,*

4

a Horticultural Sciences Department, University of Florida, Gainesville, FL, USA

${ }^{\mathrm{b}}$ Mathematics and Computer Science Division, Argonne National Laboratory, Argonne, IL, USA

7 c Computation Institute, The University of Chicago, Chicago, IL, USA

8 d Department of Chemistry, University of Florida, Gainesville, FL, USA

*Corresponding author: E-mail address adha@ufl.edu (A.D. Hanson)

Abbreviations: SynBio, synthetic biology; NAD(P)HX, NAD(P)H hydrates;

\section{ABSTRACT}

The necessarily sharp focus of metabolic engineering and metabolic synthetic biology on pathways and their fluxes has tended to divert attention from the damaging enzymatic and chemical side-reactions that pathway metabolites can undergo. Although historically overlooked and underappreciated, such metabolite damage reactions are now known to occur throughout metabolism and to generate (formerly enigmatic) peaks detected in metabolomics datasets. It is also now known that metabolite damage is often countered by dedicated repair enzymes that undo or prevent it. Metabolite damage and repair are highly relevant to engineered pathway design: metabolite damage reactions can reduce flux rates and product yields, and repair enzymes can provide robust, host-independent solutions. Herein, after introducing the core principles of metabolite damage and repair, we use case histories to document how damage and repair processes affect efficient operation of engineered pathways - particularly those that are heterologous, non-natural, or cell-free. We then review how metabolite damage reactions can be predicted, how repair reactions can be prospected, and how metabolite damage and repair can be built into genome-scale metabolic models. Lastly, we propose a versatile 'plug and play' set of well-characterized metabolite repair enzymes to solve metabolite damage problems known or likely to occur in metabolic engineering and synthetic biology projects.

31 Key words: Metabolic engineering, Synthetic biology, Metabolite damage, Metabolite repair, Side32 reaction, Enzyme promiscuity 


\section{Introduction}

34 Metabolic engineering and metabolic synthetic biology (SynBio) focus on pathways and the fluxes through them, as does metabolic biochemistry in general. While essential, this focus tends to lead to an idealized, 'pathway-centric' mindset that sees enzymes as perfectly specific and their intermediates and products as the only relevant compounds in chemical space (Danchin, 2017; Lerma-Ortiz et al., 2016; de Lorenzo et al., 2015). Excessively pathway-centric thinking is problematic for metabolic engineering and SynBio as well as for basic understanding of metabolic networks because it downplays metabolism's dark underside (Golubev, 1996). In this neglected underside, metabolites continuously undergo damaging chemical and enzymatic side-reactions in vivo, and cells ceaselessly fight this damage with a suite of repair enzymes (Van Schaftingen et al., 2009). The products of metabolite damage are basically wasteful and often toxic. If allowed to accumulate, they can disrupt the function of both native and engineered pathways (Collard et al., 2016; Schwander et al., 2016).

After decades on the margins, metabolite damage reactions and the matching repair enzymes are now entering mainstream metabolic biochemistry, and examples of damage and repair are being uncovered at an increasing rate (reviewed by Hanson et al., 2016; Keller et al., 2015; Linster et al., 2013; Van Schaftingen et al., 2013). There is also a growing case list of metabolic engineering and metabolic SynBio projects whose design has taken metabolite damage and repair into account - with positive outcomes. To help consolidate the place of metabolite damage and repair in engineering project design, in this review we first summarize the core principles involved using engineering-relevant examples. We then illustrate these principles in action using a series of engineering case-histories, and describe how metabolite damage and repair reactions can be predicted and modeled. Lastly, we propose a set of repair enzymes that are likely to prove useful in diverse engineering projects. Fuller treatments of metabolite damage and repair - including the iconic oxygenase and other sidereactions of the photosynthetic $\mathrm{CO}_{2}$-fixing enzyme RubisCO - are available in recent reviews (Erb and Zarzycki, 2016; Hanson et al., 2016; Linster et al., 2013).

\section{Chemical and enzymatic damage to metabolites}

61 As just noted, metabolite damage has two sources: spontaneous chemical reactions that take place

62 under in vivo conditions, and enzyme errors. These errors involve an enzyme acting, at a low rate, 63 on a substrate other than the physiological one (enzyme promiscuity or sloppiness), or catalysis of 64 an abnormal ('misfire') reaction on the physiological substrate. Spontaneous reactions may involve 65 only metabolites, i.e. small molecules, or attack by a metabolite on large molecules, i.e. proteins or 66 nucleic acids. Whether of spontaneous or enzymatic origin, damage products are essentially a wasteful diversion of pathway flux, and are often inhibitory to enzymes or otherwise actively detri- 
mental or functionally compromised (Linster et al., 2013). It is important to note at the outset that metabolite damage reactions are favored by high metabolic flux rates and large pool sizes (Ito et al., 2016; Rzem et al., 2007; Sullivan et al., 2013) because metabolic engineering approaches generally aim to achieve high fluxes and involve expanded pools. Engineering efforts thus often aggravate metabolite damage and must find ways to cope with it. While it is in principle possible to reduce damage from enzyme promiscuity or misfires by enzyme engineering, in practice this is not easy because of the trade-off between improved specificity and catalytic activity (Tawfik, 2014). Another potential way to reduce damage is by sequestering chemically reactive metabolites or problematic substrates for promiscuous enzymes within multienzyme complexes (metabolons) or special compartments, but as such approaches are in their infancy they are again not easy to implement (Singleton et al., 2014; Young et al., 2017). Figure 1 illustrates the various types of metabolite damage using examples from three core sectors of primary metabolism: cofactors, sugar phosphates and amino acids. Damage reactions like those in Figure 1 - chemical or enzymatic - occur in almost all cells almost all the time, and in at least some cases are accelerated by suboptimal conditions (Intlekofer et al., 2017; Piedrafita et al., 2015).

\subsection{Cofactor damage}

$\mathrm{NADH}$ and NADPH hydrates (Fig. 1A) are formed by a side-reaction of the core glycolytic enzyme glyceraldehyde 3-phosphate dehydrogenase and also spontaneously, particularly at high temperatures (Acheson et al., 1988; Marbaix et al., 2011; Oppenheimer and Kaplan, 1974). The hydrates (abbreviated $\mathrm{NAD}(\mathrm{P}) \mathrm{HX}$ ) exist as $R$ and $S$ epimers; they inhibit various dehydrogenases (Prabhakar et al., 1998; Yoshida and Dave, 1975) and consequently cannot be allowed to accumulate.

5-Formyltetrahydrofolate (Fig. 1B) is formed from 5,10-methylenetetrahydrofolate by a misfire reaction of the near-ubiquitous folate-dependent enzyme serine hydroxymethyltransferase (Stover and Schirch, 1990) and is also formed spontaneously from 5,10-methylenetetrahydrofolate at low $\mathrm{pH}$ (Baggott, 2000). 5-Formyltetrahydrofolate is potent inhibitor of folate-dependent enzymes, and therefore must be removed to prevent its build-up (Stover and Schirch, 1993).

\subsection{Sugar phosphate damage}

Methylglyoxal, also called pyruvaldehyde (Fig. 1C), forms spontaneously from the triose phosphate intermediates of glycolysis - glyceraldehyde 3-phosphate and dihydroxyacetone phosphate - via an elimination reaction that is further accelerated by a side-activity of triose phosphate isomerase (Richard, 1993). Methylglyoxal, a reactive dicarbonyl compound, is a potent glycating agent that reacts spontaneously with the amino or thiol groups of other metabolites, proteins, and DNA (Fig. 
1C) (Richarme et al., 2016; Richarme et al., 2017; Thornalley, 2008). The initial glycation products (aminocarbinols or hemithioacetals) can undergo a series of dehydrations, oxidations, and rearrangements (Maillard reactions) that produce Schiff bases, Amadori products, advanced glycation end products, and cross-links between macromolecules (Richarme et al., 2015). There is thus a cascade effect in which the initial damage product (methylglyoxal) goes on to create further damage.

4-Phosphoerythronate and 2-phospho-L-lactate (Fig. 1D) are generated by side-reactions of two glycolytic enzymes (Collard et al., 2016). 4-Phosphoerythronate is formed as a consequence of glyceraldehyde 3-phosphate dehydrogenase acting on the pentose phosphate pathway intermediate erythrose 4-phosphate, which is itself a reactive glycating agent (Van Schaftingen et al., 2012). 2-Phospho-L-lactate is formed by pyruvate kinase acting on L-lactate. 4-Phosphoerythronate inhibits the pentose phosphate pathway enzyme 6-phosphogluconate dehydrogenase and 2-phospho-L-lactate inhibits phosphofructokinase, which makes the glycolytic activator fructose-2,6-bisphosphate.

\subsection{Amino acid damage}

Deaminated glutathione (Fig. 1E), in which a keto group replaces the $\alpha$-amino group of glutathione's glutamyl moiety, is produced by a side-activity of many transaminases (Peracchi et al., 2017) and at least one decarboxylase (Novogrodsky and Meister, 1964). The ketoacid moiety of deaminated glutathione cyclizes spontaneously, giving two anomeric forms; this cyclization makes the transamination reaction that produces deaminated glutathione essentially irreversible. Deaminated glutathione may interfere with the activity of glutathione-dependent enzymes, and its formation can represent a major drain on the glutathione pool (Peracchi et al., 2017).

5-Oxoproline (also called pyroglutamate) is the lactam form of glutamate (Fig. 1F). It is formed via spontaneous cyclization of glutamine (Tritsch and Moore, 1962), glutamate (Park et al., 2001), and the proline biosynthesis intermediate Y-glutamyl phosphate (Orlowski and Meister, 1971). 5-Oxoproline forms very readily from glutamine; the conversion rate is $10 \%$ per day in physiological conditions (pH 7.2, moderate ionic strength, $37^{\circ} \mathrm{C}$ ) (Tritsch and Moore, 1962). Although the mechanism is unclear, 5-oxoproline is widely toxic (Niehaus et al., 2017; Park et al., 2001). In addition to being a universal metabolite damage product, 5-oxoproline is a normal metabolite of glutathione in eukaryotes (Kumar and Bachhawat, 2012).

\subsection{Damage products pervade metabolomics profiles}

Chemically or enzymatically damaged metabolites are almost surely major contributors to the 'dark matter' of metabolomes, until now largely ignored (Fiehn et al., 2011; Showalter et al., 2017). All the 
damage product examples above are detectable by targeted or untargeted GC-MS or LC-MS metabolomics analyses (Collard et al., 2016; Niehaus et al., 2014; Peracchi et al., 2017; Ringling and Rychlik, 2013; Shaheen et al., 2014; Thornalley and Rabbani, 2014; van der Werf et al., 2007). It follows that the same should be true of the plethora of other damage products that side-reactions can generate from the enormous chemical diversity of metabolites (Fiehn et al., 2011; Peracchi et al., 2017). A major obstacle to identifying such damage products is that - like most of the examples above - they are not in metabolite libraries and they cannot be purchased. In a later section (5.1) we show how computational chemistry can help overcome this obstacle by predicting the structures and properties of damage products for which no experimental data are yet available.

\section{Damage repair enzymes}

Damage repair enzymes, defined broadly, either undo damage by reconverting damaged molecules to normal ones, or dispose safely of harmful damage products by converting them to harmless ones. These activities are also called metabolite proofreading and damage pre-emption, respectively (Linster et al., 2013; Van Schaftingen et al., 2013). We illustrate repair principles using the enzymes that repair the cofactor, sugar phosphate, and amino acid damage products described above (Fig. 1).

\subsection{Cofactor repair}

NADHX and NADPHX are reconverted to NADH and NADPH by the sequential action of NAD(P)HX epimerase and $\operatorname{NAD}(P) H X$ dehydratase, which both occur in all domains of life (Marbaix et al., 2011; Niehaus et al., 2014) (Fig. 1A). The dehydratase is specific for the $S$ epimer of NAD(P)HX (Acheson et al., 1988) and the epimerase facilitates conversion of the $R$ form to the $S$ form used by the dehydratase. Epimerization also proceeds spontaneously, so that the epimerase may not always be needed (Acheson et al., 1988). The dehydratase is ATP- or ADP-dependent (Marbaix et al., 2011), illustrating the general principle that repair mechanisms often have an energetic cost (Linster et al. 2013).

5-Formyltetrahydrofolate is reconverted to the mainstream folate 5,10-methylenetetrahydrofolate by 5-formyltetrahydrofolate cyclo-ligase in an ATP-dependent reaction (Stover and Schirch, 1993) (Fig. 1B). This repair enzyme occurs in all domains of life. Certain prokaryotes instead use an enzyme that transfers the 5-formyl group to glutamate, yielding tetrahydrofolate (Jeanguenin et al., 2010).

\subsection{Sugar phosphate repair}

Methylglyoxal has long been known to be rendered harmless by conversion to D-lactate, via lactoylglutathione, by the near-ubiquitous enzymes glyoxalase I and II acting in tandem (Thornalley, 1990) (Fig. 1C). Recent work has uncovered another near-ubiquitous enzyme, DJ-1, that repairs methylgly- 
oxal-glycated arginine, lysine, and cysteine residues in proteins by acting on the early glycation intermediates (aminocarbinols or hemithioacetals) to release lactate, thereby forestalling the Maillard casade (Richarme et al., 2015) (Fig. 1C). DJ-1 also repairs methylglyoxal-glycated guanine bases in nucleotides and nucleic acids, again releasing lactate (Richarme et al., 2017). Because DNA glycation raises mutation frequencies, DJ-1 helps maintain DNA integrity. DJ-1 can in addition repair glyoxal-glycated proteins and nucleic acids (Richarme et al., 2015; Richarme et al., 2017).

4-Phosphoerythronate and 2-phospho-L-lactate are both hydrolyzed by a widely conserved phosphatase (PGP in mammals, Pho13 in yeast), yielding innocuous products (Collard et al., 2016) (Fig. 1D). There are probably similar phosphatases in plants and bacteria (Beaudoin and Hanson, 2016).

\subsection{Amino acid repair}

Deaminated glutathione is safely hydrolyzed to the normal metabolites $\alpha$-ketoglutarate and cysteinylglycine by the enzyme Nit1 (Fig. 1E), which occurs in eukaryotes and many prokaryotes (Peracchi et al., 2017). The cysteinylglycine product can be hydrolyzed by various peptidases.

5-Oxoproline is hydrolyzed to glutamate by ATP-dependent 5-oxoprolinases (Niehaus et al., 2017; Van der Werf et al., 1971) (Fig. 1F). The eukaryotic-type 5-oxoprolinase is a single gene product whereas the prokaryotic-type enzyme has three subunits encoded by different genes (Niehaus et al., 2017).

\section{Engineering case histories}

Designing an engineering solution depends on first diagnosing the problem. As stressed in the Introduction, metabolite damage has historically been underdiagnosed. Nevertheless, there are good examples from metabolic engineering and SynBio where metabolite damage problems were diagnosed correctly and solved. Four such cases are summarized below. Collectively, these cases illustrate three general principles: (i) Without the appropriate metabolite repair enzymes, an engineered metabolic pathway may not function efficiently, and can spark genome instability that leads to its own inactivation. (ii) Installing a non-native pathway in a platform organism always runs some risk of failure because the platform lacks sufficient repair capacities, and the more alien the pathway is to the platform, the higher the risk. (iii) This risk is even higher in synthetic pathways consisting only of purified pathway enzymes because such systems have no repair capacities at all.

\subsection{1,3-Propanediol production}


Anaerobic fermentation of glycerol to 1,3-propanediol can be engineered in Escherichia coli using four Klebsiella pneumoniae enzymes: glycerol dehydratase and 3-hydroxypropionaldehyde reductase to produce 1,3-propanediol; and glycerol dehydrogenase and dihydroxyacetone kinase to provide the NADH needed and to yield dihydroxyacetone phosphate as a carbon and energy source for growth (Tong et al., 1991) (Fig. 2A). Growth and 1,3-propanediol production were found to be limited by methylglyoxal accumulation; the limitation was relieved by overexpressing glyoxalase I, which improved cell growth and raised 1,3-propanediol production by 50\% (Zhu et al., 2001) (Fig. 2A). Glyoxalase $I$ is considered the rate-limiting step in the glyoxalase pathway (Takasawa et al., 2011). This case shows how problematic engineering strategies that expand triose phosphate pools can be, due to the inevitable accompanying rise in methylglyoxal formation (see section 2.2). It is also a paradigmatic example of metabolite repair being incorporated into the metabolic engineering design cycle.

\subsection{Mevalonate pathway}

Operation of the yeast mevalonate pathway in $E$. coli can be compromised by buildup of its isopentenyl and dimethylallyl diphosphate intermediates, which are electrophilic damage agents that cause cells to cease growth or to mutate, silencing the pathway (Martin et al., 2003; Withers et al., 2007). Prospecting for a solution by screening a Bacillus subtilis genomic library for genes that overcome isopentenyl/dimethylallyl diphosphate toxicity identified two repair phosphatases, NudF and YhfR, that hydrolyze the diphosphates to harmless isopentenols (Fig. 2B) (Withers et al., 2007). NudF and the similar enzyme NudB were later creatively repurposed to build non-natural pathways to isopentenol biofuels (Chou and Keasling, 2012; Zheng et al., 2013). Besides demonstrating damage diagnosis and parts prospecting for repair enzymes, this case highlights how a non-native pathway can destabilize its own genes via metabolite damage-driven hypermutation (de Lorenzo, 2014).

\subsection{1,4-Butanediol production}

A pathway from succinyl-CoA or a-ketoglutarate to the non-natural product 1,4-butanediol was engineered in E. coli by installing five heterologous enzymes (Yim et al., 2011) (Fig. 2C). One of several undesired by-products of this alien pathway was $\mathrm{y}$-butyrolactone, formed from the intermediate 4hydroxybutyryl-CoA via a spontaneous damage reaction (Fig. $2 \mathrm{C}$ ). The problem of $\mathrm{y}$-butyrolactone accumulation was solved by installing a heterologous $\mathrm{Y}$-butyrolactonase (Chen et al., 2010) to hydrolyze the lactone to 4-hydroxybutyrate, thus recycling it back into the 1,4-butanediol synthesis pathway (Burgard et al., 2016) (Fig. 2C). This case illustrates how absence of a repair enzyme from the platform organism can degrade the efficiency of an alien pathway. As 4-hydroxybutyryl-CoA is not a native E. coli metabolite, E. coli cells would not be predicted to have a dedicated repair enzyme for $\mathrm{Y}$-butyrolactone; the engineering outcomes confirmed that such an enzyme was indeed lacking. 


\subsection{Synthetic $\mathrm{CO}_{2}$ fixation pathway}

244 A twelve-step, non-natural $\mathrm{CO}_{2}$ fixation cycle (the $\mathrm{CETCH}$ cycle) was built from purified recombinant enzymes originating from nine different organisms (Schwander et al., 2016). The cycle output was measured as malate production. To obtain effective cycle operation, it was necessary to deal with various side-reactions. One such side-reaction, mediated by the cycle enzyme $\beta$-methylmalyl-CoA lyase, was the formation of malyl-CoA from glyoxylate and acetyl-CoA (Fig. 2D) (Erb et al., 2010). Installation of a repair enzyme - malyl-CoA thioesterase from Rhodobacter sphaeroides (Erb et al., 2010) - prevented the buildup of malyl-CoA (Fig. 2D) (Schwander et al., 2016). This case emphasizes that a miscellany of enzymes used to assemble a non-natural pathway will by definition encounter metabolites to which they were never exposed in their native hosts, providing many opportunities for new side-reactions arising from enzyme promiscuity. Such promiscuous reactions can in principle be predicted at the design stage, as discussed below (section 5.1). Another issue raised indirectly by the CETCH cycle and other systems comprised of purified enzymes (e.g., Bujara et al., 2010; Opgenorth et al., 2016) is that carbonyl intermediates such as glyoxylate (Fig. 2D) - a highly reactive glycating agent (Dutta et al., 2007) - are virtually certain to react with enzymes over time, leading in some cases to their inactivation. The same is likely true of the $\mathrm{CETCH}$ cycle intermediate acrylylCoA, a very reactive electrophile that attacks sulfhydryl groups (Curson et al., 2014).

\subsection{Chemistry of secondary pathways}

262 The biosynthetic pathways to secondary metabolites produce a vast array of diverse and complex small molecules. The products commonly include therapeutics, making these pathways high-value targets for SynBio and metabolic engineering efforts. In contrast to primary metabolism, very little is known about metabolite repair enzymes in secondary metabolism, and metabolite repair has rarely been utilized in secondary pathway engineering. Indeed, secondary product biosynthesis genes, particularly in microbes, are often strictly clustered and the function of each of the gene products can be assigned, with no metabolite repair machinery apparently present. This suggests that repair may not be widespread in secondary pathways - which seems paradoxical, given the many chemically reactive intermediates in these pathways. One explanation may be metabolic tunneling (channeling) of highly reactive intermediates amongst pathway enzymes, e.g. the strictosidine aglycone common to monoterpene indole alkaloid pathways (Stavrinides et al., 2015). Also, secondary pathways typically operate in the native host with low efficiency, producing mixtures of products with relatively low yields of each. This low output presumably suffices for the biological need/use of the natural product and increased efficiency (via repair of intermediates) is not needed. In contrast, metabolic engineer- 
repair machinery into engineered systems will be useful. Somewhat similar considerations apply to

278 the analogous area of engineering efficient pathways to degrade recalcitrant non-natural chemical

279 structures that contaminate the environment (Dvořák et al., 2017). As with the biosynthetic inter280 mediates of many therapeutics (some of which can become contaminants), the intermediates of degradation may be totally alien to engineered microbes, again making repair machinery useful.

283 One established example of repair in secondary metabolism is the occurrence of external (type II) 284 thioesterases in biosynthetic pathways to polyketide (PK) and nonribosomal peptide (NRP) second285 ary metabolites (homologous enzymes function in fatty acid pathways) (Horsman et al., 2016). The enzymatic machinery to PKs and NRPs consists of large modular, multidomain synth(et)ase proteins in which the substrates and pathway intermediates are attached to small carrier domains via thioester linkages to a phosphopantetheine prosthetic group. Sources of errors or stalls in the pathway can be misloading of incorrect building blocks by pathway enzymes or by the promiscuous action of the post-translational modifying phosphopantetheine transferase (PPTase) (Fig. 2E) (Beld et al., 2014). In their canonical reaction, PPtases use coenzyme A (CoA) as substrate to add a thiol-containing phosphopantetheine arm to the carrier domain, but promiscuous activity can potentially use acetylCoA or other cellular acyl-CoAs instead, and so add an acylated phosphopantetheine. Either of these error pathways could stall the assembly line and/or produce aberrant products. Type II thioesterases can hydrolyze these aberrant intermediates, restoring the free holo-synth(et)ase. Proposals for mechanism include inherent specificity for incorrect versus correct thioesters or use of low level, non-specific activity acting on kinetically stable, stalled machinery (Heathcote et al., 2001). Indeed, a majority of PK and NPR biosynthetic gene clusters contain an external thioesterase and removing the gene significantly reduces natural product yield in several systems (Kotowska and Pawlik, 2014).

\section{Predicting and modeling metabolite damage and repair}

\section{5.1. Predicting metabolite damage reactions}

303 The diversity of potential metabolite damage reactions makes these reactions challenging to predict. 304 Fortunately, numerous computational tools have been developed to systematically predict new pot305 ential reactions and metabolites in biological systems for the purpose of proposing novel metabolic pathways; these tools include BNICE (Hatzimanikatis et al., 2005), EnviPath (Wicker et al., 2016), Retropath (Fehér et al., 2014), and ReactPRED (Sivakumar et al., 2016). Starting from known biochemical reactions, they all derive generic reaction rules that define reactive chemical substructures and the corresponding substructure in the products. These reaction rules can then be applied to alternative substrates in order to predict new potential reactions and products in a manner similar to the "find and replace" function in a text editor. The rules can be derived from manual curation of 
312 known reactions (e.g. BNICE, EnviPath) or generated algorithmically (Retropath, ReactPRED); both

313 methods depend on having a source database of biochemical data such as MetaCyc (Caspi et al.,

314 2016) and KEGG (Kanehisa et al., 2014) from which to derive the rules. The reaction rule approach

315 has been used to predict enzyme promiscuity reactions and products by applying reaction rule sets 316 to public databases such as KEGG and EcoCyc (Jeffryes et al., 2015). The resulting database of 317 promiscuity products is particularly useful for proposing novel metabolites that correspond to unan318 notated features in untargeted metabolomics datasets (Allard et al., 2017).

This cheminformatic reaction rule approach was also recently extended to the prediction of potential 321 damage chemistry (Lerma-Ortiz et al., 2016). Because spontaneous reactions are poorly represent322 ed in MetaCyc, KEGG, and similar databases (just 3\% of reactions in MetaCyc are currently annotat323 ed as spontaneous), this effort required the development of a new database of known spontaneous 324 reactions, merging the 398 spontaneous reactions from MetaCyc with 366 reactions gathered from 325 the primary literature. A total of 106 reaction rules were derived from these spontaneous reactions, 326 and were applied to a database of known metabolites to generate $>72,000$ predicted damage products. These predicted damage products and the reactions that form them comprise the Chemical 328 Damage Metabolic In silico Network Expansion (or CD-MINE) (Lerma-Ortiz et al., 2016). The CDMINE offers a rich set of damage possibilities that can be filtered with metabolomic or genomic evidence to identify potential damage problems and to design repair solutions.

\subsection{Prospecting for repair enzymes}

333 Repair enzymes can be prospected by classical or computational strategies. Classical approaches were recently reviewed (Hanson et al., 2016; Linster et al., 2013) so are only briefly outlined here, focusing on those helpful in engineering. Computational approaches are then covered in more detail.

Classical bioprospecting strategies for repair enzymes are essentially manual, require expert knowledge, and are of two types: biochemical and genomic (Linster et al., 2013). In both cases, it is necessary to first diagnose what the damage product is, and preferably what the damage reaction is. This information is mined from the literature or obtained by metabolome analysis. The biochemical strategy envisions potential repair pathways for the damage product, searches for the enzyme activities involved, and clones the corresponding enzymes. NAD(P)HX dehydratase (section 3.1), the PGP/Pho13 phosphatase (section 3.2), and ethylmalonyl-CoA decarboxylase (Table 1) were found in this way. The comparative genomic strategy rests on the 'guilt by association' principle (Hanson et 
ivities generate damage products, (ii) genes for synthesis or utilization of metabolites that undergo damage (chemical or enzymatic), and (iii) genes specifying other enzymes in the same repair pathway. $\mathrm{NAD}(\mathrm{P}) \mathrm{HX}$ epimerase and glutamate formyltransferase (section 3.1) and prokaryotic 5-oxoprolinase (section 3.3) were discovered by this type of approach.

In addition to these classical methods, the power of cheminformatics algorithms to predict enzymatic reactions can be readily applied to predict potential repair reactions for damaged metabolites. Figure 3 illustrates how the repair reactions (all hydrolytic) from the engineering case studies in Sections 4.1-4.4 can be retrospectively predicted by generalized reaction rules. Even if a specific repair reaction has already been hypothesized based on other lines of evidence, cheminformatics can be used to ensure that a more comprehensive set of reaction possibilities are considered. For example, each of the damaged metabolites from the above four case studies exists in the MINE database of potential novel enzyme reactions (Jeffryes et al., 2015), allowing mining of this database for other potential repair pathways.

Finally, once a repair reaction has been proposed, cheminformatics can help discover candidate enzymes that catalyze it. The EC-BLAST tool (Rahman et al., 2014) can compare a proposed reaction to known biochemical reactions from KEGG and output a list of reactions that are similar to the query. This similarity is based on either matching the functional groups of the reactants and products in the two reactions or on the bonds that are broken and formed in each case. Critically, not all enzymes that mediate similar reactions are sequence homologs. EC-BLAST can thus identify a more complete range of candidate enzymes with similar substrate range and function to the proposed repair reaction than simply searching within a single protein family.

\subsection{Incorporating metabolite damage and repair in genome-scale metabolic models}

The above considerations show how numerous potential damage reactions, and subsequent potential repair pathways, can be spawned just from the portion of the biochemical reaction space that is known and well understood. Many of these damage reactions will never cause problems in either a wild-type or a heavily engineered cell, but in certain cases an otherwise innocuous damage mechanism may become problematic when a heavily engineered cell begins operating in a state that is far removed from its natural homeostatic condition. Identifying which of the overwhelming number of potential damage reactions may fit in this category can be a great challenge. Fortunately, metabolic modeling algorithms are well equipped to address this challenge. Potential damage reactions, and associated predicted repair pathways, may be integrated into metabolic models using algorithms like gapfilling (Satish Kumar et al., 2007) and flux variability analysis (Mahadevan and Schilling, 2003) to 
determine: (i) which potential damage and repair pathways are likely to be operational and relevant to a particular host organism; (ii) which damage and repair pathways are likely to function when a target pathway is overexpressed or transferred to a new host; (iii) the potential impact on product yields and growth rates when various amounts of flux pass through a damage and repair pathway; and (iv) potential biomarkers that may appear in transcriptomes or metabolomes when a particular damage or repair activity is taking place. Models can also help engineers to identify modifications to the cell that could mitigate problematic metabolite damage or induce a potential repair mechanism.

Given the potential for metabolic models to aid in the management of metabolite damage that may arise as a result of modifications made during metabolic engineering, it is no surprise that damage and repair pathways have begun to appear in the most sophisticated genome-scale metabolic models. Specifically, the iJO1366 E. coli model (Orth et al., 2011) includes 57 spontaneous reactions, many of which fit the criteria for metabolite damage. Twenty one of these reactions lead to products that are subsequently enzymatically converted to a more innocuous form, i.e. are handled by repair mechanisms. Despite these advances, E. coli and other platform or chassis organisms almost surely have many undiscovered metabolite damage reactions and repair pathways (Linster et al., 2013), which obviously cannot yet be included in models. Therefore much remains to be done in this area.

\section{A damage repair enzyme kit}

The above damage and repair examples and engineering case histories demonstrate that metabolite damage is a clear and present danger to all engineered pathway systems, especially non-natural or cell-free ones, and that enough is known to design solutions to at least the most obvious damage problems. The value of applying damage and repair principles in pathway design is gaining recognition (Erb et al., 2017), as captured by the statement: "the concept of metabolic proofreading has only rarely been considered for synthetic pathway design...We believe that this design principle should be included more systematically in metabolic engineering in the future" (Schwander et al., 2016).

To facilitate adoption of damage and repair principles, Table 1 lists damage reactions to a score of central metabolites and a matching set of repair enzymes, with references to their characterization and engineering applications. About half of these enzymes have already been covered in section 3 and are documented there; the others are briefly documented in Table 1 itself. Table 1 is not a full inventory of reported metabolite damage reactions and repair enzymes; there are many more (Hanson et al., 2016; Lerma-Ortiz et al., 2016; Linster et al., 2013). Rather, it focuses on enzymes that seem likely to be widely useful when engineering primary metabolism in diverse organisms or in vitro. Fluxes through the pools of the central metabolites subject to the damage reactions in Table 1 
are generally high. This tends to favor side-reactions because, as noted in Section 2, the more the flux through a canonical enzymatic reaction, the more the flux through that enzyme's promiscuous side-reactions (Rzem et al., 2007). Central metabolites are thus the most likely ones to need repair. The enzymes in Table 1 are nothing like a panacea, but singly or in combination they can take care of various widespread damage problems and so constitute useful parts for engineering design.

\section{Acknowledgements}

This work was supported by the National Science Foundation [grant numbers MCB-1611711, MCB1611952] and by an endowment from the C.V. Griffin Sr. Foundation.

\section{References}

Acheson, S.A., Kirkman, H.N., Wolfenden, R., 1988. Equilibrium of 5,6-hydration of NADH and mechanism of ATP-dependent dehydration. Biochemistry 27(19), 7371-7375. http://dx.doi.org/10.1021/bi00419a030.

Aliprandi, P., Navarro, E., Raynaud, C., Bestel Corre, G., Soucaille, P., 2017. New microorganism and method for the production of 1,2-propanediol based on NADPH dependent acetol reductase and improved NADPH supply. United States Patent Application Publication No. US2017 0145446 A1

Allard, P.-M., Genta-Jouve, G., Wolfender, J.-L., 2017. Deep metabolome annotation in natural products research: towards a virtuous cycle in metabolite identification, Curr. Opin. Chem. Biol. 36, 40-49. http://dx.doi.org/10.1016/j.cbpa.2016.12.022.

Baggott, J.E., 2000. Hydrolysis of 5,10-methenyltetrahydrofolate to 5-formyltetrahydrofolate at $\mathrm{pH}$ 2.5 to 4.5. Biochemistry 39(47), 14647-14653. http://dx.doi.org/10.1021/bi001362m.

Beaudoin, G.A., Hanson, A.D., 2016. A guardian angel phosphatase for mainline carbon metabolism. Trends Biochem. Sci. 41, 893-894. https://doi.org/10.1016/j.tibs.2016.08.005.

Beld, J., Sonnenschein, E.C., Vickery, C.R., Noel, J.P., Burkart, M.D., 2014. The phosphopantetheinyl transferases: catalysis of a post-translational modification crucial for life. Nat. Prod. Rep. 31(1) 61-108. https://doi.org/10.1039/c3np70054b.

Bujara, M., Schümperli, M., Billerbeck, S., Heinemann, M., Panke, S., 2010. Exploiting cell-free systems: Implementation and debugging of a system of biotransformations. Biotechnol. Bioeng. 106(3), 376-389. https://doi.org/10.1002/bit.22666.

Burgard, A., Burk, M.J., Osterhout, R., Van Dien, S., Yim, H., 2016. Development of a commercial scale process for production of 1,4-butanediol from sugar. Curr. Opin. Biotechnol. 42, 118-125. http://dx.doi.org/10.1016/i.copbio.2016.04.016. 
451

452

453

454

455

456

457

458

459

460

461

462

463

464

465

466

467

468

469

470

471

472

473

474

475

476

477

478

479

480

481

482

483

484

Cai, H., Clarke, S., 1999. A novel methyltransferase catalyzes the methyl esterification of transaconitate in Escherichia coli. J. Biol. Chem. 274(19), 13470-13479. http://dx.doi.org/10.1074/jbc.274.19.13470.

Caspi, R., Billington, R., Ferrer, L., Foerster, H., Fulcher, C.A., Keseler, I.M., Kothari, A., Krummenacker, M., Latendresse, M., Mueller, L.A., Ong, Q., Paley, S., Subhraveti, P., Weaver, D.S., Karp, P.D., 2016. The MetaCyc database of metabolic pathways and enzymes and the BioCyc collection of pathway/genome databases. Nucleic Acids Res. 44(D1), D471-D480. http://dx.doi.org/10.1093/nar/gkv1164.

Chen, B., Fan, L.Q., Xu, J.H., Zhao, J., Zhang, X., Ouyang, L.M., 2010. Biocatalytic properties of a recombinant Fusarium proliferatum lactonase with significantly enhanced production by optimal expression in Escherichia coli. Appl. Biochem. Biotechnol. 162(3), 744-756.

https://doi.org/10.1007/s12010-009-8819-1.

Chou, H.H., Keasling, J.D., 2012. Synthetic pathway for production of five-carbon alcohols from isopentenyl diphosphate. Appl. Environ. Microbiol. 78(22), 7849-7855. http://dx.doi.org/10.1128/AEM.01175-12.

Collard, F., Baldin, F., Gerin, I., Bolsée, J., Noël, G., Graff, J., Veiga-da-Cunha, M., Stroobant, V., Vertommen, D., Houddane, A., Rider, M.H., Linster, C.L., Van Schaftingen, E., Bommer, G.T., 2016. A conserved phosphatase destroys toxic glycolytic side products in mammals and yeast. Nat. Chem. Biol. 12(8), 601-607. http://dx.doi.org/10.1038/nchembio.2104.

Curson, A.R., Burns, O.J., Voget, S., Daniel, R., Todd, J.D., Mclnnis, K., Wexler, M., Johnston, A.W., 2014. Screening of metagenomic and genomic libraries reveals three classes of bacterial enzymes that overcome the toxicity of acrylate. PLoS One 9(5), e97660.

http://dx.doi.org/10.1371/journal.pone.0097660.

Danchin, A., 2017. Coping with inevitable accidents in metabolism. Microb. Biotechnol. 10(1), 57-72. http://dx.doi.org/10.1111/1751-7915.12461.

Delpierre, G., Rider, M.H., Collard, F., Stroobant, V., Vanstapel, F., Santos, H., Van Schaftingen, E., 2000. Identification, cloning, and heterologous expression of a mammalian fructosamine-3-kinase. Diabetes 49(10), 1627-1634. https://doi.org/10.2337/diabetes.49.10.1627.

Dutta, U., Cohenford, M.A., Guha, M., Dain, J.A., 2007. Non-enzymatic interactions of glyoxylate with lysine, arginine, and glucosamine: a study of advanced non-enzymatic glycation like compounds. Bioorg. Chem. 35(1), 11-24. https://doi.org/10.1016/j.bioorg.2006.07.005.

Dvořák, P., Nikel, P.I., Damborský, J., de Lorenzo V., 2017. Bioremediation 3.0: Engineering pollutant-removing bacteria in the times of systemic biology. Biotechnol. Adv. 35(7), 845-866. https://doi.org/10.1016/i.biotechadv.2017.08.001. 
485

486

487

488

489

490

491

492

493

494

495

496

497

498

499

500

501

502

503

504

505

506

507

508

509

510

511

512

513

514

515

516

517

518

Erb, T.J., Frerichs-Revermann, L., Fuchs, G., Alber, B.E., 2010. The apparent malate synthase activity of Rhodobacter sphaeroides is due to two paralogous enzymes, (3S)-malyl-coenzyme A (CoA)/B-methylmalyl-CoA lyase and (3S)-malyl-CoA thioesterase. J. Bacteriol. 192(5), 12491258. http://dx.doi.org/10.1128/JB.01267-09.

Erb, T.J., Jones, P.R., Bar-Even, A., 2017. Synthetic metabolism: metabolic engineering meets enzyme design. Curr. Opin. Chem. Biol. 37, 56-62. http://dx.doi.org/10.1016/j.cbpa.2016.12.023.

Erb, T.J., Zarzycki, J., 2016. Biochemical and synthetic biology approaches to improve photosynthetic $\mathrm{CO}_{2}$-fixation. Curr. Opin. Chem. Biol. 34, 72-79. http://dx.doi.org/10.1016/j.cbpa.2016.06.026.

Fehér, T., Planson, A.G., Carbonell, P., Fernández-Castané, A., Grigoras, I., Dariy, E., Perret, A., Faulon, J.L., 2014. Validation of RetroPath, a computer-aided design tool for metabolic pathway engineering. Biotechnol. J. 9(11), 1446-1457.

http://dx.doi.org/10.1002/biot.201400055.

Fiehn, O., Barupal, D.K., Kind, T., 2011. Extending biochemical databases by metabolomic surveys. J. Biol. Chem. 286(27), 23637-23643. https://doi.org/10.1074/jbc.R110.173617.

Fortpied, J., Gemayel, R., Stroobant, V., van Schaftingen, E., 2005. Plant ribulosamine/erythrulosamine 3-kinase, a putative protein-repair enzyme. Biochem. J. 388(3), 795-802. https://doi.org/10.1042/BJ20041976.

Gemayel, R., Fortpied, J., Rzem, R., Vertommen, D., Veiga-da-Cunha, M., Van Schaftingen, E., 2007. Many fructosamine 3-kinase homologues in bacteria are ribulosamine/erythrulosamine 3kinases potentially involved in protein deglycation. FEBS J. 274(17), 4360-4374. https://doi.org/10.1111/j.1742-4658.2007.05948.x.

Golubev, A.G., 1996. The other side of metabolism: a review. Biochemistry (Mosc.) 61(11), 20182039.

Hanson, A.D., Henry, C.S., Fiehn, O., de Crécy-Lagard, V., 2016. Metabolite damage and metabolite damage control in plants. Annu. Rev. Plant Biol. 67, 131-152. http://dx.doi.org/10.1146/annurev-arplant-043015-111648.

Hanson, A.D., Pribat, A., Waller, J.C., de Crécy-Lagard, V., 2009. 'Unknown' proteins and 'orphan' enzymes: the missing half of the engineering parts list - and how to find it. Biochem. J. 425(1), 1-11. http://dx.doi.org/10.1042/BJ20091328.

Hatzimanikatis, V., Li, C., Ionita, J.A., Henry, C.S., Jankowski, M.D., Broadbelt, L.J., 2005. Exploring the diversity of complex metabolic networks. Bioinformatics 21(8), 1603-1609. https://doi.org/10.1093/bioinformatics/bti213. 
519

520

521

522

523

524

525

526

527

528

529

530

531

532

533

534

535

536

537

538

539

540

541

542

543

544

545

546

547

548

549

550

551

552

Heathcote, M.L., Staunton, J., Leadlay, P.F., 2001. Role of type II thioesterases: evidence for removal of short acyl chains produced by aberrant decarboxylation of chain extender units. Chem. Biol. 8(2), 207-220. https://doi.org/10.1016/S1074-5521(01)00002-3.

Horsman, M.E., Hari, T.P., Boddy, C.N., 2016. Polyketide synthase and non-ribosomal peptide synthetase thioesterase selectivity: logic gate or a victim of fate? Nat. Prod. Rep. 33(2), 183-202. http://dx.doi.org/10.1039/c4np00148f.

Intlekofer, A.M., Wang, B., Liu, H., Shah, H., Carmona-Fontaine, C., Rustenburg, A.S., Salah, S., Gunner, M.R., Chodera, J.D., Cross, J.R., Thompson, C.B., 2017. L-2-Hydroxyglutarate production arises from noncanonical enzyme function at acidic pH. Nat. Chem. Biol. 13(5), 494-500. http://dx.doi.org/10.1038/nchembio.2307.

Ito, T., Yamauchi, A., Hemmi, H., Yoshimura, T., 2016. Ophthalmic acid accumulation in an Escherichia coli mutant lacking the conserved pyridoxal 5'-phosphate-binding protein YggS. J. Biosci. Bioeng. 122(6), 689-693. http://dx.doi.org/10.1016/j.jbiosc.2016.06.010.

Jeanguenin, L., Lara-Núñez, A., Pribat, A., Mageroy, M.H., Gregory, J.F. 3rd, Rice, K.C., de CrécyLagard, V., Hanson, A.D., 2010. Moonlighting glutamate formiminotransferases can functionally replace 5-formyltetrahydrofolate cycloligase. J. Biol. Chem. 285(53), 41557-41566. https://doi.org/10.1074/jbc.M110.190504.

Jeffryes, J.G., Colastani, R.L., Elbadawi-Sidhu, M., Kind, T., Niehaus, T.D., Broadbelt, L.J., Hanson, A.D., Fiehn, O., Tyo, K.E., Henry, C.S., 2015. MINEs: open access databases of computationally predicted enzyme promiscuity products for untargeted metabolomics. J. Cheminform. 7, 44. https://doi.org/10.1186/s13321-015-0087-1.

Kanehisa, M., Goto, S., Sato, Y., Kawashima, M., Furumichi, M., Tanabe, M., 2014. Data, information, knowledge and principle: back to metabolism in KEGG. Nucleic Acids Res. 42, D199D205. https://doi.org/10.1093/nar/gkt1076.

Keller, M.A., Piedrafita, G., Ralser, M., 2015. The widespread role of non-enzymatic reactions in cellular metabolism. Curr. Opin. Biotechnol. 34, 153-161.

http://dx.doi.org/10.1016/j.copbio.2014.12.020.

Kildegaard, K.R., Hallström, B.M., Blicher, T.H., Sonnenschein, N., Jensen, N.B., Sherstyk, S., Harrison, S.J., Maury, J., Herrgård, M.J., Juncker, A.S., Forster, J., Nielsen, J., Borodina, I., 2014. Evolution reveals a glutathione-dependent mechanism of 3-hydroxypropionic acid tolerance. Metab. Eng. 26, 57-66. http://dx.doi.org/10.1016/j.ymben.2014.09.004.

Kotowska, M., Pawlik, K. 2014. Roles of type II thioesterases and their application for secondary metabolite yield improvement. Appl. Microbiol. Biotechnol. 98(18) 7735-7746. http://dx.doi.org/10.1007/s00253-014-5952-8. 
Krasnikov, B.F., Nostramo, R., Pinto, J.T., Cooper, A.J., 2009. Assay and purification of omegaamidase/Nit2, a ubiquitously expressed putative tumor suppressor, that catalyzes the deamidation of the $\alpha$-keto acid analogues of glutamine and asparagine. Anal. Biochem. 391(2), 144150. http://dx.doi.org/10.1016/j.ab.2009.05.025.

Kumar, A., Bachhawat, A.K., 2012. Pyroglutamic acid: throwing light on a lightly studied metabolite. Curr. Sci. 102(2), 288-297. http://www.jstor.org/stable/24083854.

Lee, B.C., Gladyshev, V.N., 2011. The biological significance of methionine sulfoxide stereochemistry. Free Radic. Biol. Med. 50(2), 221-227. http://dx.doi.org/10.1016/j.freeradbiomed.2010.11.008.

Lerma-Ortiz, C., Jeffryes, J.G., Cooper, A.J., Niehaus, T.D., Thamm, A.M., Frelin, O., Aunins, T., Fiehn, O., de Crécy-Lagard, V., Henry, C.S., Hanson, A.D., 2016. 'Nothing of chemistry disappears in biology': the Top 30 damage-prone endogenous metabolites. Biochem. Soc. Trans. 44(3), 961-971. http://dx.doi.org/10.1042/BST20160073.

Linster, C.L., Noël, G., Stroobant, V., Vertommen, D., Vincent, M.F., Bommer, G.T., Veiga-daCunha, M., Van Schaftingen, E., 2011. Ethylmalonyl-CoA decarboxylase, a new enzyme involved in metabolite proofreading. J. Biol. Chem. 286(50), 42992-43003. http://dx.doi.org/10.1074/jbc.M111.281527.

Linster, C.L., Van Schaftingen, E., Hanson, A.D., 2013. Metabolite damage and its repair or preemption. Nat. Chem. Biol. 9(2), 72-80. http://dx.doi.org/doi:10.1038/nchembio.1141.

de Lorenzo, V., 2014. From the selfish gene to selfish metabolism: revisiting the central dogma. Bioessays 36(3), 226-235. http://dx.doi.org/10.1002/bies.201300153.

de Lorenzo, V., Sekowska, A., Danchin, A., 2015. Chemical reactivity drives spatiotemporal organisation of bacterial metabolism. FEMS Microbiol. Rev. 39(1), 96-119. http://dx.doi.org/10.1111/1574-6976.12089.

Mahadevan, R., Schilling, C.H., 2003. The effects of alternate optimal solutions in constraint-based genome-scale metabolic models. Metab. Eng. 5(4), 264-276. https://doi.org/10.1016/j.ymben.2003.09.002.

Marbaix, A.Y., Noël, G., Detroux, A.M., Vertommen, D., Van Schaftingen, E., Linster, C.L., 2011. Extremely conserved ATP- or ADP-dependent enzymatic system for nicotinamide nucleotide repair. J. Biol. Chem. 286(48), 41246-41252. http://dx.doi.org/10.1074/jbc.C111.310847.

Martin, V.J., Pitera, D.J., Withers, S.T., Newman, J.D., Keasling, J.D., 2003. Engineering a mevalonate pathway in Escherichia coli for production of terpenoids. Nat. Biotechnol. 21(7), 796-802. http://dx.doi.org/10.1038/nbt833.

Niehaus, T.D., Elbadawi-Sidhu, M., de Crécy-Lagard, V., Fiehn, O., Hanson, A.D., 2017. Discovery of a widespread prokaryotic 5-oxoprolinase that was hiding in plain sight. J. Biol. Chem. 
http://dx.doi.org/10.1074/jbc.M117.805028.

Niehaus, T.D., Gerdes, S., Hodge-Hanson, K., Zhukov, A., Cooper, A.J., ElBadawi-Sidhu, M., Fiehn, O., Downs, D.M., Hanson, A.D., 2015. Genomic and experimental evidence for multiple metabolic functions in the RidA/YjgF/YER057c/UK114 (Rid) protein family. BMC Genomics 16, 382. https://doi.org/10.1186/s12864-015-1584-3.

Niehaus, T.D., Richardson, L.G., Gidda, S.K., ElBadawi-Sidhu, M., Meissen, J.K., Mullen, R.T., Fiehn, O., Hanson, A.D., 2014. Plants utilize a highly conserved system for repair of NADH and NADPH hydrates. Plant Physiol. 165(1), 52-61. https://doi.org/10.1104/pp.114.236539.

Novogrodsky, A., Meister, A., 1964. Control of aspartate beta-decarboxylase activity by transamination. J Biol Chem 239(3), 879-888.

Opgenorth, P.H., Korman, T.P., Bowie, J.U., 2016. A synthetic biochemistry module for production of bio-based chemicals from glucose. Nat. Chem. Biol. 12(6), 393-395.

https://doi.org/10.1038/nchembio.2062.

Oppenheimer, N.J., Kaplan, N.O., 1974. Glyceraldehyde-3-phosphate dehydrogenase catalyzed hydration of the 5-6 double bond of reduced $\beta$-nicotinamide adenine dinucleotide ( $\beta-N A D H$ ). Formation of $\beta$-6-hydroxy-1,4,5,6-tetrahydronicotinamide adenine dinucleotide. Biochemistry 13(23), 4685-4694. http://dx.doi.org/10.1021/bi00720a002.

Orlowski, M., Meister, A., 1971. Partial reactions catalyzed by gamma-glutamylcysteine synthetase and evidence for an activated glutamate intermediate. J. Biol. Chem. 246(23), 7095-7105.

Orth, J.D., Conrad, T.M., Na, J., Lerman, J.A., Nam, H., Feist, A.M., Palsson, B.Ø., 2011. A comprehensive genome-scale reconstruction of Escherichia coli metabolism - 2011. Mol. Syst. Biol. 7, 535. http://dx.doi.org/10.1038/msb.2011.65.

Park, C.B., Lee, S.B., Ryu, D.D., 2001. L-Pyroglutamate spontaneously formed from L-glutamate inhibits growth of the hyperthermophilic archaeon Sulfolobus solfataricus. Appl. Environ. Microbiol. 67(8), 3650-3654. http://dx.doi.org/10.1128/AEM.67.8.3650-3654.2001.

Peracchi, A., Veiga-da-Cunha, M., Kuhara, T., Ellens, K.W., Paczia, N., Stroobant, V., Seliga, A.K., Marlaire, S., Jaisson, S., Bommer, G.T., Sun, J., Huebner, K., Linster, C.L., Cooper, A.J.L., Van Schaftingen. E., 2017. Nit1 is a metabolite repair enzyme that hydrolyzes deaminated glutathione. Proc. Natl. Acad. Sci. USA 114(16), E3233-E3242. http://dx.doi.org/10.1073/pnas.1613736114.

Piedrafita, G., Keller, M.A., Ralser, M., 2015. The impact of non-enzymatic reactions and enzyme promiscuity on cellular metabolism during (oxidative) stress conditions. Biomolecules 5(3), 2101-2122. http://dx.doi.org/10.3390/biom5032101. 
621 Prabhakar, P., Laboy, J.I., Wang, J., Budker, T., Din, Z.Z., Chobanian, M., Fahien, L.A., 1998. Effect

622

623

624

625

626

627

628

629

630

631

632

633

634

635

636

637

638

639

640

641

642

643

644

645

646

647

648

649

650

651

652

653

654

of NADH-X on cytosolic glycerol-3-phosphate dehydrogenase. Arch. Biochem. Biophys. 360(2), 195-205. https://doi.org/10.1006/abbi.1998.0939.

Rahman, S.A., Cuesta, S.M., Furnham, N., Holliday, G.L., Thornton, J.M., 2014. EC-BLAST: a tool to automatically search and compare enzyme reactions. Nat. Methods 11(2), 171-174. http://dx.doi.org/10.1038/nmeth.2803.

Richard, J.P., 1993. Mechanism for the formation of methylglyoxal from triosephosphates. Biochem. Soc. Trans. 21(2), 549-553. http://dx.doi.org/10.1042/bst0210549.

Richarme, G., Liu, C., Mihoub, M., Abdallah, J., Leger, T., Joly, N., Liebart, J.C., Jurkunas, U.V., Nadal, M., Bouloc, P., Dairou, J., Lamouri, A., 2017. Guanine glycation repair by DJ-1/Park7 and its bacterial homologs. Science 357(6347), 208-211.

http://dx.doi.org/10.1126/science.aag1095.

Richarme, G., Marguet, E., Forterre, P., Ishino, S., Ishino, Y., 2016. DJ-1 family Maillard deglycases prevent acrylamide formation. Biochem. Biophys. Res. Commun. 478(3), 1111-1116. http://dx.doi.org/10.1016/j.bbrc.2016.08.077.

Richarme, G., Mihoub, M., Dairou, J., Bui, L.C., Leger, T., Lamouri, A., 2015. Parkinsonism-associated protein DJ-1/Park7 is a major protein deglycase that repairs methylglyoxal- and glyoxalglycated cysteine, arginine, and lysine residues. J. Biol. Chem. 290(3), 1885-1897. https://doi.org/10.1074/jbc.M114.597815.

Ringling, C., Rychlik, M., 2013. Analysis of seven folates in food by LC-MS/MS to improve accuracy of total folate data. Eur. Food Res. Technol. 236(1), 17-28.

https://doi.org/10.1007/s00217-012-1849-x.

Rzem, R., Van Schaftingen, E., Veiga-da-Cunha, M., 2006. The gene mutated in L-2-hydroxyglutaric aciduria encodes L-2-hydroxyglutarate dehydrogenase. Biochimie 88(1), 113-116. https://doi.org/10.1016/j.biochi.2005.06.005.

Rzem, R., Vincent, M.F., Van Schaftingen, E., Veiga-da-Cunha, M., 2007. L-2-hydroxyglutaric aciduria, a defect of metabolite repair. J. Inherit. Metab. Dis. 30(5), 681-689. https://doi.org/10.1007/s10545-007-0487-0.

Satish Kumar, V., Dasika, M.S., Maranas, C.D., 2007. Optimization based automated curation of metabolic reconstructions. BMC Bioinformatics 8, 212.

https://doi.org/10.1186/1471-2105-8-212.

Schwander, T., Schada von Borzyskowski, L., Burgener, S., Cortina, N.S., Erb, T.J., 2016. A synthetic pathway for the fixation of carbon dioxide in vitro. Science 354(6314), 900-904. http://dx.doi.org/10.1126/science.aah5237. 
655

656

657

658

659

660

661

662

663

664

665

666

667

668

669

670

671

672

673

674

675

676

677

678

679

680

681

682

683

684

685

686

687

688

Shaheen, F., Shmygol, A., Rabbani, N., Thornalley, P.J., 2014. A fluorogenic assay for methylglyoxal. Biochem. Soc. Trans. 42(2), 548-555. http://dx.doi.org/10.1042/BST20140028.

Showalter, M.R., Cajka, T., Fiehn, O., 2017. Epimetabolites: discovering metabolism beyond building and burning. Curr. Opin. Chem. Biol. https://doi.org/10.1016/j.cbpa.2017.01.012.

Singleton, C., Howard, T.P., Smirnoff, N., 2014. Synthetic metabolons for metabolic engineering. J. Exp. Bot. 65(8), 1947-1954. https://doi.org/10.1093/jxb/eru050.

Sivakumar, T.V., Giri, V., Park, J.H., Kim, T.Y., Bhaduri, A., 2016. ReactPRED: a tool to predict and analyze biochemical reactions. Bioinformatics 32(22), 3522-3524. https://doi.org/10.1093/bioinformatics/btw491.

Stavrinides, A., Tatsis, E.C., Foureau, E., Caputi, L., Kellner, F., Courdavault, V., O'Connor, S.E., 2015. Unlocking the diversity of alkaloids in Catharanthus roseus: nuclear localization suggests metabolic channeling in secondary metabolism. Chem. Biol. 22(3), 336-341. https://doi.org/10.1016/j.chembiol.2015.02.006.

Stover, P., Schirch, V., 1990. Serine hydroxymethyltransferase catalyzes the hydrolysis of 5,10methenyltetrahydrofolate to 5-formyltetrahydrofolate. J. Biol. Chem. 265(24), 14227-14233.

Stover, P., Schirch, V., 1993. The metabolic role of leucovorin. Trends Biochem. Sci. 18(3), 102106. https://doi.org/10.1016/0968-0004(93)90162-G.

Sullivan, L.B., Martinez-Garcia, E., Nguyen, H., Mullen, A.R., Dufour, E., Sudarshan, S., Licht, J.D., Deberardinis, R.J., Chandel, N.S., 2013. The proto-oncometabolite fumarate binds glutathione to amplify ROS-dependent signaling. Mol. Cell. 51(2), 236-248. https://doi.org/10.1016/j.molcel.2013.05.003.

Takasawa, R., Tao, A., Saeki, K., Shionozaki, N., Tanaka, R., Uchiro, H., Takahashi, S., Yoshimori, A., Tanuma, S., 2011. Discovery of a new type inhibitor of human glyoxalase I by myricetin-based 4-point pharmacophore. Bioorg. Med. Chem. Lett. 21(14), 4337-4342. https://doi.org/10.1016/j.bmcl.2011.05.046.

Tawfik, D.S., 2014. Accuracy-rate tradeoffs: how do enzymes meet demands of selectivity and catalytic efficiency? Curr. Opin. Chem. Biol. 21, 73-80. https://doi.org/10.1016/i.cbpa.2014.05.008.

Thornalley, P.J., 2008. Protein and nucleotide damage by glyoxal and methylglyoxal in physiological systems. Role in ageing and disease. Drug metabol. Drug Interact. 23(1-2), 125-150. https://doi.org/10.1515/DMDI.2008.23.1-2.125.

Thornalley, P.J., 1990. The glyoxalase system: new developments towards functional characterization of a metabolic pathway fundamental to biological life. Biochem. J. 269(1), 1-11. https://doi.org/10.1042/bj2690001. 
Thornalley, P.J., Rabbani, N., 2014. Assay of methylglyoxal and glyoxal and control of peroxidase interference. Biochem. Soc. Trans. 42(2), 504-510. https://doi.org/10.1042/BST20140009.

Tong, I.T., Liao. H.H., Cameron, D.C., 1991. 1,3-Propanediol production by Escherichia coli expressing genes from the Klebsiella pneumoniae dha regulon. Appl. Environ. Microbiol. 57(12), 35413546.

Tritsch, G.L., Moore, G.E., 1962. Spontaneous decomposition of glutamine in cell culture media. Exp. Cell. Res. 28(2), 360-364. https://doi.org/10.1016/0014-4827(62)90290-2.

Van der Werf, M.J., Overkamp, K.M., Muilwijk, B., Coulier, L., Hankemeier, T., 2007. Microbial metabolomics: toward a platform with full metabolome coverage. Anal. Biochem. 370(1), 17-25. https://doi.org/10.1016/j.ab.2007.07.022.

Van der Werf, P., Orlowski, M., Meister, A., 1971. Enzymatic conversion of 5-oxo-L-proline (L-pyrrolidone carboxylate) to L-glutamate coupled with cleavage of adenosine triphosphate to adenosine diphosphate, a reaction in the Y-glutamyl cycle. Proc. Natl. Acad. Sci. USA 68(12), 29822985.

Van Schaftingen, E., Collard, F., Wiame, E., Veiga-da-Cunha, M., 2012. Enzymatic repair of Amadori products. Amino Acids 42(4), 1143-1150. http://dx.doi.org/10.1007/s00726-010-0780-3.

Van Schaftingen, E., Rzem, R., Marbaix, A., Collard, F., Veiga-da-Cunha, M., Linster, C.L., 2013. Metabolite proofreading, a neglected aspect of intermediary metabolism. J. Inherit. Metab. Dis. 36(3), 427-434. http://dx.doi.org/10.1007/s10545-012-9571-1.

Van Schaftingen, E., Rzem, R., Veiga-da-Cunha, M., 2009. L-2-Hydroxyglutaric aciduria, a disorder of metabolite repair. J. Inherit. Metab. Dis. 32(2), 135-142. http://dx.doi.org/10.1007/s10545-008-1042-3.

Wicker, J., Lorsbach, T., Gütlein, M., Schmid, E., Latino, D., Kramer, S., Fenner, K., 2016. enviPath - The environmental contaminant biotransformation pathway resource. Nucleic Acids Res. 44(D1), D502-D508. https://doi.org/10.1093/nar/gkv1229.

Wilson, S.M., Gleisten, M.P., Donohue, T.J., 2008. Identification of proteins involved in formaldehyde metabolism by Rhodobacter sphaeroides. Microbiology 154(1), 296-305. http://dx.doi.org/10.1099/mic.0.2007/011346-0.

Withers, S.T., Gottlieb, S.S., Lieu, B., Newman, J.D., Keasling, J.D., 2007. Identification of isopentenol biosynthetic genes from Bacillus subtilis by a screening method based on isoprenoid precursor toxicity. Appl. Environ. Microbiol. 73(19), 6277-6283.

http://dx.doi.org/10.1128/AEM.00861-07.

Yim, H., Haselbeck, R., Niu, W., Pujol-Baxley, C., Burgard, A., Boldt, J., Khandurina, J., Trawick, J.D., Osterhout, R.E., Stephen, R., Estadilla, J., Teisan, S., Schreyer, H.B., Andrae, S., Yang, 
T.H., Lee, S.Y., Burk, M.J., Van Dien, S., 2011. Metabolic engineering of Escherichia coli for direct production of 1,4-butanediol. Nat. Chem. Biol. 7(7), 445-452.

https://doi.org/10.1038/nchembio.580.

Yoshida, A., Dave, V., 1975. Inhibition of NADP-dependent dehydrogenases by modified products of NADPH. Arch. Biochem. Biophys. 169(1), 298-303. https://doi.org/10.1016/0003-9861(75)90344-6.

Young, E.J., Burton, R., Mahalik, J.P., Sumpter, B.G., Fuentes-Cabrera, M., Kerfeld, C.A., Ducat, D.C., 2017. Engineering the bacterial microcompartment domain for molecular scaffolding applications. Front. Microbiol. 8, 1441. https://doi.org/10.3389/fmicb.2017.01441.

Zheng, Y., Liu, Q., Li, L., Qin, W., Yang, J., Zhang, H., Jiang, X., Cheng, T., Liu, W., Xu, X., Xian, M., 2013. Metabolic engineering of Escherichia coli for high-specificity production of isoprenol and prenol as next generation of biofuels. Biotechnol. Biofuels. 6, 57. http://dx.doi.org/10.1186/1754-6834-6-57.

Zhu, M.M., Skraly, F.A., Cameron, D.C., 2001. Accumulation of methylglyoxal in anaerobically grown Escherichia coli and its detoxification by expression of the Pseudomonas putida glyoxalase I gene. Metab. Eng. 3(3), 218-225. https://doi.org/10.1006/mben.2001.0186. 
Fig. 1. Examples of metabolite damage and repair reactions from central metabolism. Red arrows are damage reactions and blue arrows are repair reactions. $(A) N A D(P) H$ damage and repair. $\mathrm{NAD}(\mathrm{P}) \mathrm{HX}$ dehydratase is ATP-dependent in eukaryotes (as shown) but ADP-dependent in prokaryotes. GAPDH, glyceraldehyde 3-phosphate dehydrogenase; (B) 5,10-Methenyltetrahydrofolate $(5,10-\mathrm{CH}=\mathrm{THF})$ damage and repair. SHMT, serine hydroxymethyltransferase; FT, glutamate formyltransferase; 5-FCL, 5-formyltetrahydrofolate cyclo-ligase; 5-CHO-THF, 5-formyltetrahydrofolate; THF, tetrahydrofolate, $\mathrm{pABG}, p$-aminobenzoylglutamate. The dashed blue arrow represents several reactions of one-carbon metabolism that can convert tetrahydrofolate to 5,10-methenyltetrahydrofolate. (C) Triose phosphate damage and repair. DHAP, dihydroxyacetone phosphate; TPI, triose phosphate isomerase; GSH, glutathione; Glol, glyoxalase I; Gloll, glyoxalase II. (D) Damage to erythrose 4-phosphate and lactate, and repair by PGP phosphatase. The dashed red arrow represents the conversion of 1,4-bisphosphoerythronate (1,4-BP-erythronate) to 4-phosphoerythronate by phosphoglycerate kinase or acylphosphatase (Collard et al., 2016). P, phosphate. (E) Glutathione damage and repair. The cyclic form of deaminated glutathione predominates in solution (Peracchi et al., 2017). (F) Spontaneous damage reactions leading to 5-oxoproline, and repair by 5-oxoprolinase.

Fig. 2. Examples of the use of metabolite repair enzymes in metabolic engineering and SynBio projects. Red arrows are damage reactions and blue arrows are repair reactions. Dashed arrows represent more than one reaction. (A) Overexpression of glyoxalase I (boxed) boosted flux in an engineered anaerobic glycerol fermentation pathway to 1,3-propanediol in $E$. coli by preventing buildup of the triose phosphate damage product methylglyoxal. (B) Expression of the phosphatases NudF or YhfR relieved toxicity of an engineered mevalonate pathway in $E$. coli by hydrolyzing its isopentenyl diphosphate (IDP) and dimethylallyl diphosphate (DMADP) intermediates to the corresponding alcohols. IDP and DMADP are colored red to indicate that they are reactive electrophiles. (C) Installation of a lactonase to support an engineered 1,4-butanediol pathway in $E$. coli increased product yield by countering spontaneous formation of $\mathrm{y}$-butryrolactone from the pathway intermediate 4hydroxybutyryl-CoA. (D) Addition of malyl-CoA thioesterase (MCT) to support the synthetic in vitro $\mathrm{CETCH}$ cycle of $\mathrm{CO}_{2}$ fixation facilitated effective cycle operation by hydrolyzing malyl-CoA, a

769 byproduct formed by a promiscuous reaction of the cycle enzyme $\beta$-methylmalyl-CoA lyase (MCL).

770 (E) Inclusion of an external (type II) thioesterase (TE) in biosynthetic pathways to polyketides or non-

771 ribosomal peptides prevents errors or stalls in the pathway caused by misloading of incorrect 772 building blocks by pathway enzymes, or by the promiscuous action of phosphopantetheine transfer- 
773 ase (PPTase). The thioesterase selectively hydrolyzes these aberrant intermediates, regenerating 774 the free holo-synth(et)ase.

775

776 Fig. 3. Repair reactions from engineering case studies and the generalized reaction rules that 777 predict them. The figure depicts the generalized reaction rules from BNICE that predict four repair 778 reactions from the engineering case study section. For each rule a depiction was generated with 779 ChemAxon MarvinSketch. An "A" in the image may be any non-hydrogen atom. The "W" near an 780 atom (for wildcard) indicates that the atom may or may not be member of a ring while a "0" indicates 781 that the atom is in no rings. Some atoms may have multiple valid bond patterns and these alternat782 ives are indicated by the corresponding R\#. 


\section{Table 1}

A 'plug and play' set of repair enzymes with likely applications in engineering core metabolism

\begin{tabular}{|c|c|c|}
\hline Damage reactions & Repair enzymes & Uses in engineering \\
\hline Triose- $\mathrm{P}^{\mathrm{a}} \rightarrow$ methylglyoxylate $[\mathrm{S}, \mathrm{E}]$ & Glyoxalase I and II (section 3.2) & (section 4.1) \\
\hline Erythrose 4-P, ribose 5-P $\rightarrow$ glycations [S] & $\begin{array}{l}\text { Ribulosamine/erythrulosamine 3-kinases (deglycation) } \\
\text { (Fortpied et al., 2005; Gemayel et al., 2007) }\end{array}$ & \\
\hline Fructose 6-P $\rightarrow$ glycations [S] & Fructosamine 3-kinase (deglycation) (Delpierre et al., 2000) & \\
\hline Lactate $\rightarrow$ 2-P lactate $[E]$ & PGP/Pho13 phosphatase (section 3.2) & \\
\hline cis-Aconitate $\rightarrow$ trans-aconitate $[\mathrm{S}, \mathrm{E}]$ & trans-Aconitate methyltransferase (Cai and Clarke, 1999) & \\
\hline$\alpha$-Ketoglutarate $\rightarrow$ L-a-hydroxyglutarate $[E]$ & L- $\alpha$-Hydroxyglutarate dehydrogenase (Rzem et al., 2006) & \\
\hline Oxidations $\rightarrow$ formaldehyde, other aldehydes [S, E] & $\begin{array}{l}\text { Formaldehyde-activating enzyme/formaldehyde dehydrogenase/ } \\
\text { S-formylglutathione hydrolase (Wilson et al., 2008) }\end{array}$ & (Kildegaard et al., 2014) \\
\hline Butyryl-CoA $\rightarrow$ ethylmalonyl-CoA [E] & Ethylmalonyl-CoA decarboxylase (Linster et al., 2011) & \\
\hline Free/bound methionine $\rightarrow$ methionine sulfoxides [S] & Methionine sulfoxide reductases (Lee and Gladyshev, 2011) & \\
\hline Amino acids $\rightarrow$ imines/enamines [E] & RidA enamine deaminases (Niehaus et al., 2015) & \\
\hline \multicolumn{3}{|l|}{ Cofactor metabolism } \\
\hline $\mathrm{NAD}(\mathrm{P}) \mathrm{H} \rightarrow \mathrm{NAD}(\mathrm{P}) \mathrm{HX}[\mathrm{S}, \mathrm{E}]$ & $\mathrm{NAD}(\mathrm{P}) \mathrm{HX}$ dehydratase/NAD $(\mathrm{P}) \mathrm{HX}$ epimerase (section 3.1) & (Aliprandi et al., 2017) \\
\hline $\begin{array}{l}5,10-\text { Methenyltetrahydrofolate } \rightarrow \text { 5-formyltetrahydro- } \\
\text { folate }[S, E]\end{array}$ & $\begin{array}{l}\text { 5-Formyltetrahydrofolate cyclo-ligase or glutamate formimino- } \\
\text { transferase (section 3.1) }\end{array}$ & \\
\hline
\end{tabular}

a Abbreviations: -P, phosphate; CoA, coenzyme A; S, spontaneous reaction; E, enzymatic side-reaction. 
i

Hers:

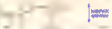

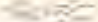

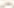

$\sqrt{2}+2$

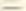

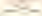
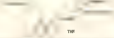

ne

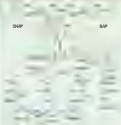

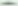

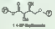

$=$
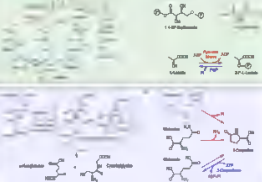


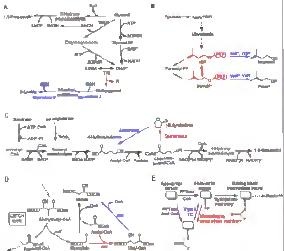


